Please do not remove this page

RMIT

UNIVERSITY

\title{
An exploration of counter-intuitive conceptual structures in organizational stories
}

Smith, Aaron

https://researchrepository.rmit.edu.au/esploro/outputs/9921858198301341/filesAndLinks?institution=61RMIT_INST\&index=null

Smith, A. (2009). An exploration of counter-intuitive conceptual structures in organizational stories. Journal of Sport Management, 23(4), 483-510.

https://researchrepository.rmit.edu.au/discovery/fulldisplay/alma9921858198301341/61RMIT_INST:Resea rchRepository

Document Version: Published Version

Repository homepage: https://researchrepository.rmit.edu.au

(c) 2009 Human Kinetics, Inc.

Downloaded On 2023/04/26 12:48:33 +1000

Please do not remove this page 
Smith, A 2009, 'An exploration of counter-intuitive conceptual structures in organizational stories', Journal of Sport Management, vol. 23, no. 4, pp. 483-510.

\title{
An Exploration of Counter-Intuitive Conceptual Structures in Organizational Stories
}

\author{
Aaron Smith \\ RMIT University
}

\begin{abstract}
Although it is well accepted that organizational stories communicate cultural meaning, little is known about their optimal composition for memorability and subsequent transmission. This interpretive study sought to explore the features of organizational stories which contribute to their cognitive optimality. Boyer's $(1994,2001)$ cognitive optimality hypothesis was employed, which predicts the presence of minimally counter-intuitive (MCI) concepts in culturally recurrent stories. Employing a sample of nine Australian sport organizations, 27 in-depth interviews were conducted. The organizational stories collected in this research, when defined by Gabriel's (2000) criteria, contained MCI concepts. The data analysis revealed three emergent codes that reflect the cognitive structure of MCI concept organizational stories: Agency, Membership Markers, and Ritual. This article extends cognitive optimality theory by demonstrating how it can be employed to understand the mechanisms underpinning the cultural transmission of concepts. It adds to theoretical explanations seeking to explain the construction and composition of sport organizational culture by predicting a heavier density of counterintuitive content in stories and other cultural content.
\end{abstract}

Cultural studies have persuasively demonstrated that the propagation of ideas and beliefs are heavily influenced by contextual factors and social variables. This is exemplified by obvious differences in language, music, sport, and business practice between cultures. In an organizational context, the term culture refers to a collection of fundamental values and attitudes that are common to members of a social group, and which subsequently set the behavioral standards or norms for all members (Ogbonna \& Harris, 2002; Pettigrew, 1979). While cognitive scientists agree that contextual and social forces shape beliefs, they also argue that certain beliefs are more easily transmitted because they fall on fertile ground. In this way of looking at the transmission of ideas and beliefs, the human mind is seen as predisposed to host particular kinds of concepts. It is not just the environment which contributes to the catchiness of ideas, but the match between their specific composition and the host potential of the mind.

Smith is with the College of Business, Royal Melbourne Institute of Technology University, Melbourne 3001, Australia. 
In organizations, some ideas never really get off the ground, while others enjoy temporary fashionability. A minority of those ideas which have enjoyed some success prove robust enough to become entrenched components in organizational culture, the permanent inhabitants in a group of minds. Cognitive theorists sometimes liken the transmission of cultural knowledge to the virulence of a contagious disease. Infections spread not just because of exposure, but also because of the susceptibility of those exposed (Dawkins, 1982; Norenzayan \& Atran, 2002a; Sperber, 1996). The successful transmission of ideas, concepts, and beliefs in organizations may therefore be considered a function of both cultural exposure and cognitive receptivity. The term cognitive is used in reference to mental information processing including, for example, such elements as attention, perception, learning, memory and decision-making (Eysenck \& Keane, 2005). In broad terms, it is a better understanding of the role of cognition in the transmission of cultural information in sport organizations that motivates this study.

The unique perspective conferred through a cognitive interpretation is that it regards culture as not merely a material phenomenon, but also a cognitive representation of material phenomena (D'Andrade, 1995). This means that taking a cognitive perspective in an organization brings with it the assumption that physical things, events, and people are not independent of the minds that perceive them. We are therefore interested in the mental representations which organizational members create of the world in which they work. Mental representations are useful to study for at least two reasons. First, they literally stand for something, symbolizing the mental correlates of a domain or category of thought. Second, representations contain implicit content about the domain of interest. Understanding this content provides an insight into the way an individual perceives important aspects of the organizational world within which they work.

Boyer (1994) argued that the mind is susceptible to hosting certain kinds of ideas and representations. Central to Boyer's (1994) theory is the notion of counter-intuitive concepts; that is, ideas that are easily acquired and represented by a mind may be considered cognitively optimal. The cognitive optimality theory proposes that when a counter-intuitive concept is embedded within a group of intuitive concepts, the total conceptual unit holds a transmission advantage, subsequently enhancing their recurrence. In simple terms, ideas that are completely intuitive are not as memorable as those that have an element of counter-intuitivity as well. According to Boyer (1994, 2000), certain patterns in concepts can have a dramatic impact on their memorability and subsequent transmission. Moreover, the most culturally recurrent concepts are those which align with the mind's peculiar system of thought and memory. Specifically, Boyer's (1994) thesis hinges upon the importance of what he calls minimally counter-intuitive (MCI) concepts. These concepts violate intuitive expectations about the world and its contents. For example, most adults have developed an intuitive schema about the category or domain we might label "animals." Within this domain there would likely be a set of representations about the concept "dog." In practical terms we all have intuitive expectations about the behavior of a dog we might encounter, even though we may have never met it before. Boyer (2000) would argue that for a dog to violate the intuitive representations we have accumulated, it would have to do something counter-intuitive, like walk around on two legs. A dog walking on two legs would 
constitute a minor violation to an intuitive concept, or a minimally counter-intuitive concept. However, given that this is the only violation and the dog otherwise behaves according to our intuitive expectations, then Boyer (2000) would propose that the dog in question will be memorable. When the idea of this dog is passed along to others, it will be more easily remembered and subsequently propagated. This stands in contrast to a maximally counter-intuitive concept which violates numerous aspects of a domain, like a dog that can walk, talk, and fly.

The cognitive optimality hypothesis predicts that when an idea involves the addition of a small component of counter-intuitiveness that is inconsistent with normal expectations about a domain, memorability, and transmission are maximized. In an organizational context, stories that involve ordinary characters who behave in predictable and expected ways are faced with a transmission disadvantage compared with those that also contain MCI concepts. Thus, minimal counterintuitive content offers a slender window of possibility that can assist the acquisition and transmission of beliefs, concepts, and ideas.

The majority of work related to the cognitive optimality of beliefs has been undertaken by cognitive theorists with regard to religious concepts, and popular urban myths and legends (Atran \& Norenzayan, 2004; Barrett \& Nyhof, 2001; Boyer, 1994; Boyer \& Ramble, 2001; Heath, Bell, \& Sternberg, 2001; Pyysiäinen, 2002; Pyysiäinen, Lindeman, \& Honkela, 2003; Sperber, 1997). However, the cognitive optimality hypothesis has had little exposure in organizational settings. In this study, we are interested in the features of cognitive representations contained in stories told in sport organizations, with a particular emphasis on exploring the role of MCI concepts. An exploratory account of the role of MCI concepts in sport organizational stories offers a platform upon which predictions about cognitive optimality might be tested. Ultimately, understanding why certain kinds of information are easily transmitted is also relevant to theories describing the impact of cultural content. In this interpretive, exploratory study employing a diverse sample of sport organizations, stories were examined for MCI concepts with the intention of revealing their indigenous structure.

The intention of this work is to make a general theoretical contribution to explaining why organizational stories are relevant sites for understanding organizational culture and behavior. An impressive amount of material has been gathered to demonstrate that organizational stories are relevant portals to viewing organizational members' social constructions of their institutional environments. However, surprisingly little is known about stories themselves and what it is about them that attaches to the minds of recipients, or subsequently encourages their transmission. A cognitive anthropology of stories rather than just a cultural inventory is therefore demanded. The local theoretical contribution involves incremental work toward a tool and interpretive device toward better understanding sport organizations, their cultures, and the behaviors that these impel. At present, it is unclear what a MCI concept would look like in a sport organizational story. From an exploratory viewpoint, if MCI concepts are present in sport organizational stories, then understanding their presence and structure could prove advantageous to revealing the transmission and impact of stories. A review of empirical work on memorability is provided next, followed by a methodological account of the study, an analysis of the findings, and discussion of its theoretical and practical implications. 


\section{Memorability and Transmission of Ideas}

The empirical evidence supporting the importance of MCI concepts to memorability is limited but suggestive. Barrett and Nyhof (2001) asked their respondents to remember and repeat stories which contained intuitive as well as MCI concepts, events, and objects. Their subsequent content-analysis of the retold stories revealed that participants could recall $92 \%$ of the MCI concept items and $71 \%$ of the exclusively intuitive items. Adding a different twist to the hypothesis, Norenzayan and Atran (2002a) found that under ordinary conditions intuitive ideas enjoyed a better immediate recall than the MCI concepts. But on the other hand, recall of MCI concepts degraded at a lower rate after immediate recall. Norenzayan and Atran speculated that MCI concepts may have a survival advantage over exclusively intuitive ideas, or those with maximally counter-intuitive elements.

Other free-recall experiments have supported Boyer's (2001) prediction that MCI concept content is necessary for the cognitive optimality of concepts. Boyer and Ramble's (2001) cross-cultural study showed that sensitivity to counter-intuitive content is universal and produces similar recall effects despite variations in belief commitment, transmission modes, and local variables. The study also revealed better recall when the intuitive violations contradicted expectations about whole categories of things, like all animals rather than just dogs.

Norenzayan, Atran, Faulkner, and Schaller (2006) tested the salience of MCI concepts in the success of cultural narratives such as myths and folktales. In experiments, MCI concept sets produced a memory advantage after a week compared with both entirely intuitive and maximally counter-intuitive idea sets. In considering the propagation of urban legends, Heath, Bell, and Sternberg (2001), found that the more shocking and disgusting the counter-intuitive content, the more likely that their subjects reported a conviction to pass them on. Here, what Berger and Heath (2005) called a 'habitat,' or set of environmental cues that encourage recall, may be important. Ideas with facilitating habitats may enjoy greater success, implying that stronger organizational cultures possess more relevant environmental cues. In addition, there is some limited evidence to suggest that cognitive optimality may not only apply to single beliefs, but also to entire belief structures (Boyer, 2001; Norenzayan \& Atran, 2002a).

The mainstay of work on MCI concepts and cognitive optimality has been regarding the transmission of religious concepts (Atran, 2002; Atran \& Norenzayan, 2004; Boyer, 2001, 2003; McCauley \& Lawson, 2002; Pyysiäinen, 2002, 2003; Whitehouse, 2004, 2005). This is because most core religious beliefs, according to Norenzayan and Atran (2002b), demand a minimal requirement for the violation of conventional notions about the world. As a consequence, religion enables individuals to imagine 'minimally impossible worlds' that serve to release fears concerning mortality. From this viewpoint, religious beliefs are memorable because they contain ideas about supernatural agents that are inherently counterintuitive, violating natural expectations about the world and its contents. On the other hand, religious beliefs are intractably grounded in factual and commonsense assumptions associated with human motivations, emotions, desires, and needs. Thus, the key to the transmission of religious beliefs is their optimal combination of attention-grabbing counter-intuitive concepts within the context of largely intuitive idea sets. In religion, a ghost may be able to pass through solid 
objects - a counter-intuitive notion — but they also satisfy most intuitive expectations in terms of their personhood, motivations, and other sensory systems (Boyer, 1994; Sperber, 1997).

Sport organizations however, are not churches and their cultures are not religions. Nevertheless, that culture and its associated belief structures impact the behavior of organizational members is beyond dispute (Beyer \& Trice, 1993; Denison, 1996; Hatch, 1993; Schein, 1985, 1988; Trice \& Beyer, 1984; Yanow, 2000). For example, beliefs such as those concerning managers' view about the controllability of organizations as well as their own efficacy can have a significant impact on their choice of strategy (Daft \& Weick, 1984). Organizational positioning has been linked to management's beliefs about the environment (Swan, 1997), while the process of innovation in organizations can also be affected by managers' belief systems (Boyer \& Ramble, 2001; Norenzayan \& Atran, 2002a; Norenzayan, Atran, Faulkner, \& Schaller, 2006). Investigating the role of MCI concepts in the transmission of beliefs in organizations warrants further study because it has a demonstrated utility in other contexts such as religion, but is little understood in the organizational arena.

Sport organizations appear, therefore, to provide a useful site to investigate cognitive optimality for several reasons. Sport organizations are ready sources of stories (Smith \& Shilbury, 2004), although that is not to suggest that there is evidence suggesting sport contexts generate more stories than other forms of organization. In addition, sport organizations offer a site for the expression of counterintuitive concepts. While again, no empirical evidence indicates that sport encourages more counter-intuitive concepts than other contexts, social and psychological studies (Fischer, 1997; Todd \& Brown, 2003; Womack, 1992), have revealed that athletes' rituals and superstitions, like wearing particular numbers on their uniforms or following certain procedures before a game, are overtly counter-intuitive. Sport organizations provide a useful site for accessing MCI concepts.

As Sosis and Alcorta (2003) observed, the belief in a supernatural agent does not fully differentiate religion from commonplace perceptual experience or from other beliefs that do not command ritualistic and dogmatic practices. Pyysiäinen (2003) proposed that the study of religion scientifically means explaining how certain counter-intuitive representations come to be selected as objects of serious belief. As Durkheim (1961[1915]) proposed, every society holds shared beliefs that are celebrated in sacred rites that increase social cohesion and solidarity.

Social institutions like sport organizations exemplify Durkheim's point on a micro scale where organizational members share common beliefs and interpretations of their own experiences as well as external events. Berger and Luckmann's (1967) phenomenological approach to the sociology of knowledge is particularly relevant to such a conception. They proposed that behavior in institutions comes about because certain actions are encouraged, reinforced, and repeated until they are patterned and habitualized; ingrained in both the performers' construction of the institution's identity and the institution's embodiment in the form of individual action. As a consequence, reality is legitimized through individuals' ongoing roleplaying leading to a plausible and meaningful social reality. Of particular salience to this work on the composition of organizational stories is Berger and Luckmann's (1967) suggestion that legitimization is pivotal to the process of transmit- 
ting already established institutional meaning to a new generation via systems of symbolic reference: "Language constructs immense edifices of symbolic representation that appear to tower over the reality of everyday life like gigantic presences from another world" (Berger \& Luckmann, 1967, p. 55). Within this schema, organizational stories may be considered central to the "social distribution of knowledge" (Berger \& Luckmann, 1967, p. 146). Stories are scripts organizational members learn to be apprenticed and habituated into their social reality.

The premise that behavior in organizations is canalized by symbolic representations that guide meaning-making is consistent with the more contemporary view that social behavior in institutions is influenced by normative and regulative forces as well as cognitive and cultural forces. Thus, to Scott (2001), the cognitive elements reflect the internal interpretive processes that individuals experience when exposed to the informal beliefs, values, and norms, as well as the formal legal, political, and economic structures. An advantage of studying organizational stories is that they offer insight into the effect of formal and informal structures as seen through the covert inner workings of individuals engaged in the process of constructing meaning.

\section{Organizational Stories as Cultural Units}

Stories are an oral or written performance involving two or more people interpreting past or anticipated experience (Boje, 1991). Stories explain events, simplify behavioral expectations, provide conceptual accounts of organizational phenomena, place characters into context, and generally offer examples that serve as heuristics. It may also be argued that contrasting stories highlight points of contention and diverging cultural priorities or subcultures. From an organizational perspective, stories affect behavior by defining characters, sequencing plots, scripting events, and enacting responses to change (Boje, 2001). Their consideration demands attention because they provide insights into the complex social worlds in which management is undertaken. Contained in organizational stories are both implicit and explicit meanings that impact organizational reality. Browning (2000) observed that stories help individuals to enact their own script within a group. It is a "collective storytelling system in which the performance of stories is a key part of members' sense-making and a means to allow them to supplement individual memories with institutional memory" (Boje, 1991, p. 106).

Boje (2001), like Weick (1995) argues that stories play an essential sensemaking function for organizational members attempting to find their way in a complex environment where ambiguity and uncertainty are real. Often for individuals, this occurs retrospectively through stories and their interpretation. Gabriel (2000, 2004) observed that organizational storytelling has conventionally been considered subservient to organizational history. He argued that while stories do not accurately reflect reality, they remain salient shapers of meaning. The view has been strongly influenced by postmodern accounts of storytelling that acknowledge the presence of multiple realities and countless stories, many of which are fragile and susceptible to a myriad of interpretations (Boje, 2001; Czarniawska, 2004; Gabriel, 2004; Hardy, Lawrence, \& Grant, 2005). 
The stream of story analysis that Boje has pioneered takes the view that organizations cannot be registered as a single story, but rather as a plurality of stories and interpretations that compete in a struggle to represent the diverse, uncertain and sometimes chaotic organizational world. That is not to suggest that defining stories is a straightforward undertaking. Gabriel (2004), for example, considers Boje's version of stories to be fragments of more important narratives which contain a clear plot and the causal resolution to problems. Czarniawska (2004) acknowledged the relevance of social context, story fragments, and forms of emergent storytelling in narratives. In the narrative conception, stories precede narratives; they exist in a kind of void between coherence and incoherence where there is a lack of a resolved personal significance that has been constructed within the social setting. Stories are accounts of incidents and events upon which narration may be layered. Swap, Leonards, Shields, and Abrams (2001) defined an organizational story as a detailed narrative of past management actions, employee interactions, or other intra- or extraorganizational events. They specified that such stories are typically communicated informally and contain a plot, characters, and a resolution. Tyler (2006) observed that stories identify new realities, unexpected dilemmas, and creative possibilities. Accordingly, they provide symbolic reference to activity and ideas that are troublesome to access or specify lucidly.

A reasonable consensus may be found in the literature to support the view that stories are conduits for sense-making and competing perspectives. The degree to which organizations are stories, or are nothing more than their stories, is less certain. The extreme of this view holds that organizations only exist as stories in the sense that they are created through discourse (Czarniawska, 2004). Hopkinson (2003) has argued that narratives construct organizations through individual constructions of self. Notwithstanding the symbolic or literal nature of the relationship between organizations and their stories, it is reasonable to suggest that they do sequence cultural history in ways that facilitate future action (Boje, 1991, 2001; Gabriel, 1995, 2000; Gardner \& Avolio, 1998; Weick, 1995). Furthermore, it has been suggested that stories stimulate vicarious experiences, reconcile the past with the present, pattern predictions for the future, encourage the projection of personal agency into organizational activity, provide interpretations of events, and channel meaning (Nair, 2002).

Poulton (2005) advocated that understanding an organization should begin with its 'genesis' story as it represents the central metaphor framing employees' perceptions of the organization. For Nair (2002), stories allow common thoughts and messages to be repeated in novel ways bypassing conversation and encouraging listeners to infer a general truth rather than pronouncing it baldly. From this perspective, stories may be seen to share norms and values, cultivate trust, share tacit information, and stimulate an emotional connection (Denning, 2000; 2002; Gargiulo, 2005, 2006). Gabriel (2000) wrote: "Stories are narratives with plots and characters, generating emotion in narrator and audience, through a poetic elaboration of symbolic material" (p. 239). Thus legitimate stories: (1) involve characters in a predicament; (2) occur in a sequence which subsequently reflects the plot and the salient features of the characters; (3) employ symbolism; (4) use poetic embellishment and embroidery; (5) have a discernable beginning, middle, and end; and (6) communicate enduring truths beyond mere facts. 
Some assumptions can be drawn from the preceding discussion. First, there is evidence to suggest that organizational stories are units of culture that contain important information about organizations and the behavior of their members. Second, while the content of stories may vary, most generic definitions of stories such as Gabriel's $(2000,2004)$, assume that they can exist in any context and will possess the same basic definitional properties. Third, interpretation is essential to understanding the contextual importance and meaning of organizational stories. Finally, less is known about how stories propagate and why some stories are memorable and recurrent and others are not. Thus, Boyer's (1994, 2000) cognitive optimality offers a useful proposition to explore in the context of organizational stories.

\section{Method}

The conceptual foundation for this exploratory research rests upon Boyer's (1994, 2000) cognitive optimality hypothesis. It predicts that the presence of MCI concepts is pivotal to the success of concept transmission. Stories containing the right balance of counter-intuitive features are hypothesized to be remembered more accurately and retold more frequently than those with exclusively intuitive features. This research therefore begins with a deductive imperative: to examine stories through the lens of the cognitive optimality hypothesis by using an operationalized specification of cognitive optimality to classify stories. In this respect, the first part of the research is closely aligned to a predetermined theoretical perspective. However, Boyer's (2000) hypothesis and his operationalized template for identifying cognitive optimality (Boyer \& Ramble, 2001), do not provide an a priori structure in which the composition of stories can be analyzed. For this reason, the analytical component of this research employed an inductive naturalistic inquiry method consistent with that advocated by Lincoln and Guba (1985) to allow for the inductive and emergent interpretation of the story data. Lincoln and Guba (1985) did, however, note that in addition to the specification of a research problem, sampling procedures, instrumentation, and data-analytic methods, a naturalistic inquiry should also outline its theoretical perspective. In this respect, the naturalistic inquiry approach used in this research differs from a grounded theory approach, which emphasizes the absence of a priori lenses, despite the fact that this study has employed a conceptual coding method (Strauss \& Corbin, 1990) that is commonly used in grounded studies. In sum, as Denis, Lamothe, and Langley (2001) showed in their work, the combination of partly deductive, theory-inspired and partly inductive, data-inspired approach can prove fruitful.

This research employed an interpretive approach reflecting the ontological assumption that stories are socially constructed and subject to diverse interpretations by organizational members as well as researchers (Deetz, 1996). Thus, socially constructed stories contain social meanings that cannot be identified objectively (Schwartzman, 1993). Stories were treated as symbols of a socially constructed culture rather than as its objective properties. The broad goal was to identify the similarities in the structure of MCI concept defined stories provided by respondents. 


\section{Organizational Sample and Data Collection}

A multiple organization, multiple respondent data set was employed, drawn from the Australian sport industry. Australian sport is characterized by a tiered system built from a club foundation, ranging from those associated with recreational participation in local competitions to those engaged in professional, national leagues. Club representatives form state sport organizations, which manage state development and infrastructure. In turn, representatives from each state form national governing sport organizations, which subsequently manage the sport from a national perspective. The sample comprised nine organizations, including three professional sport clubs competing in national league competitions, three state associations, and three national governing associations. Diversity was sought through a purposive sample across each of the three tiers of sport. Three organizations from each tier were considered the maximum practical for analyses while also providing the opportunity to sample nine different sports ensuring a diverse set of cultural features. In addition, nine organizations allowed geographical representation across the country.

Three organizational members were interviewed for each of the nine cases, including the senior-most manager (typically entitled the Chief Executive Officer or Managing Director), a junior employee, and a member of the board of governance. The purpose of this selection was to create diversity in seniority within the sample and to establish a layered view. In total, 27 semistructured, in-depth interviews of approximately one hour in duration were conducted. It is acknowledged that the number of respondents from each organizational case represents a limitation. However, given that the study's aims were focused on the construction and composition of organizational stories rather than their specific content, it was determined that a broader organizational sample would elicit a more diverse set of stories. Given the form of the data that were required, semistructured, in-depth interviews presented the only practical mechanism for collection.

It is notoriously difficult to stimulate organizational members to recount stories (Gabriel \& Griffiths, 2004). As a result, interviews were employed to gather data about events and experiences in the organizational context. To elicit organizational stories, respondents were asked to describe the characteristics of the prevailing organizational culture. As suggested by Smith and Shilbury (2004), questions were asked concerning observable aspects of culture such as symbols, jargon, heroes, rites, rituals and ceremonies, where they reflect overt representations of cultural meaning, as well as questions asking for the description and interpretation of respondents' behavioral patterns and thought systems. Thus, the collection of data emphasized the social experience that organizational culture creates by focusing on the symbolic elements of belonging to a sport organization. This method is consistent with the study of social phenomena from the perspective of symbolic interactionism and is "concerned with the meanings of events to people and the symbols they use to convey meaning" (Eaves, 2001, p. 656).

Although respondents were asked to describe the prevailing cultural characteristics based on the prompts provided by Smith and Shilbury's (2004) aspects of culture, they were not specifically asked to recount stories. However, many chose to use stories to illustrate certain points to emphasize their salience. This approach is noteworthy because it differs from other methods which emphasize the collec- 
tion of stories in situ during ethnographic observation, or from published reproductions. There were numerous advantages to studying unsolicited stories as reported by respondents in this study. First, as Boje (1991) noted, stories are most revealing when they are reported in the way in which they are actually used, that is, to communicate symbolic meaning above and beyond interpretive descriptions. In this respect, stories were used by respondents when descriptions of cultural characteristics were inadequate, or when an example was considered a superior explanation. Second, because questions were concerned with the prevailing cultural features, when respondents recounted stories, they were considered significant. This approach provided a mechanism for revealing important rather than trivial stories. Finally, the unprompted transmission of stories met Sperber's (1996) memorability test, described next.

\section{Operationalization}

The units of data collection employed were stories, self-reported by respondents during interviews. This approach is consistent with Sperber's (1996) memorability test, in which memorability as demonstrated by unprompted transmission is a necessary precondition for the success of an idea. As a result, only those stories that were recounted by organizational members without prompting were considered part of the data set. In addition, to qualify as a story, Gabriel's $(2000,2004)$ six story constituents noted earlier needed to be present.

In the organizational setting, counter-intuitive refers to circumstances, events, or behaviors that are described contrary to intuitive presumptions about domains of reality. For organizational members a domain of reality is seen as a cognitive construct where boundaries of behavior are well-defined and understood, leading individuals to make robust predictions about the behavior of others and the causality associated with events. In the organizational context, counter-intuitive is concerned with occurrences that depart significantly from intuitive expectations about reality and its contents. Stories were included in the data set for analysis when they were consistent with Boyer and Ramble's (2001) domain-breaking template. Thus, stories were included in the data set when they met the following characteristics: (1) a pointer to a particular domain or category concept; (2) an explicit representation of a violation of intuitive expectations, either a breach of relevant expectations for the category, or a transfer of expectations associated with another category; (3) a link to (nonviolated) default expectations for the category; (4) a slot for additional cultural information; and (5) a lexical label (Boyer \& Ramble, 2001).

An example is instructive in explaining how the template is wielded. A domain pointer refers to a category describing the general class to which something belongs. A sport uniform such as a jersey belongs to the category of clothing, which in turn is associated with a set of intuitive expectations about what clothes are and what can be expected from them. Second, a violation of intuitive expectations can come about as a result of two possibilities: an unexpected feature of the item compared with what would intuitively be expected from something fitting that category, such as a sport jersey that gives its wearer additional skill or luck; or when the expectations of the item are transferred from another category, such as a hockey stick that is given a name and addressed as if it were a sentient 
being. Third, a link to the default or nonviolated expectations refers to the performance of the item in accordance with normal expectations for its category. In the case of the sport jersey, this criterion is fulfilled if it behaves in all other ways as a normal item of clothing. Fourth, the potential for additional cultural information is met when the specific new information can be attached to the item. For a sport jersey, this additional cultural information might come in the form of a particular style, color, logo, and number reflective of a team and player affiliation. Fifth, the lexical label is fulfilled by the specific name given to an item, like Kobe Bryant's jersey, even though it is owned and worn by a sport fan. In summary, stories with MCI concepts contained content describing the behavior of something or someone that defied intuitive expectations in a clear way but otherwise behaved in a way consistent with what might be expected of any example from that category.

The data set therefore included stories recounted during interviews about respondents' experiences as members of the organization, met Gabriel's criteria, and fitted Boyer and Ramble's (2001) MCI concept template. Stories qualifying were the subject of data analysis. The total number of stories that initially composed the data set was 41 . Of these, just over one third (15) satisfied the MCI concept criteria and were included in the data analysis. Of the 15 stories, eight originated from the three professional sport organizations competing in national leagues, four originated from the three national governing sport organizations, and three originated from the three state governing associations.

\section{Data Analysis}

Data were inductively analyzed in a manner consistent with the naturalistic inquiry method outlined by Lincoln and Guba (1985). Interviews were transcribed and entered into the software program N-Vivo as a mechanism for organization and retrieval. Transcripts were broadly studied to gain a general familiarity of the contents in preparation for conceptual coding. Coding is the method of data analysis and organization, where analysis involves reviewing notes and audio tapes, transcribing or synthesizing them, then dissecting them meaningfully, while keeping the relations between the parts intact (Strauss \& Corbin, 1994). During this process, dominant concepts, themes, and issues were noted to form categories; these categories becoming the codes with which the transcript was interpreted and meanings developed. Thus, coding by using keywords and concepts was used to categorize and classify the text. These codes reduced the data and highlighted trends, themes, patterns, and causal processes. Coding was undertaken in three stages: open, axial, and selective (Strauss \& Corbin, 1994). These three coding methods are not different, but sequential and interrelated requiring the breaking down, examining, comparing, conceptualizing, and categorizing of data (Miles \& Huberman, 1994).

\section{Data Trustworthiness}

Data credibility was sought through a form of investigator triangulation where two individuals were involved in the interviewing process. As Lincoln and Guba (1985, p. 307) observed, multiple investigators as part of a team help to keep each other "honest." This was achieved through peer debriefing where the interviewers 
subjected their working hypotheses to the scrutiny and analysis of a noninvolved colleague. In addition, all interview transcripts were sent to respondents as a "member check" to confirm their faithful reproduction of the conversation. Transferability was sought through the provision of careful detail concerning the research methods, contexts, and assumptions underlying the study. A purposive sample was employed and the conceptual constructs, coding themes, labels, and categories used in the study were rigorously outlined so that they might be transposed to other research contexts. In addition, contextual data such as annual reports, written descriptions of the physical environment, historical developments, and current issues identified on organizations' websites concerning each of the participating organizations were collected to help locate the data within a practical framework that assisted in assessing potential MCI concepts against a backdrop of organizational norms. A selection of this contextual information is included here to reveal the research environment and foreshadow whether findings can be justifiably applied to other sport organizational settings. As such, "fittingness" (Lincoln \& Guba, 1985, p. 124) can be judged.

Dependability was sought through purposive sampling which emphasizes the application of judgment and deliberate effort to locate representative samples including both common and divergent perspectives. Finally, 'check-coding,' a technique where in this case two researchers separately coded the same data and subsequently come together to compare codes, was employed to enhance reliability and confirmability (Boyer \& Ramble, 2001). A working reliability score was calculated by dividing the total number of coding agreements by the total number of agreements plus disagreements. This process was performed at regular intervals until reliability reached a satisfactory level. Intercoder agreement was considered reliable when it reached $90 \%$, as recommended by Miles and Huberman (1994).

\section{Results}

The results of this exploratory study show that MCI concepts are present in some organizational stories. Of the total number of stories recorded during interviews, approximately one-third (15) met the specified MCI concept criteria and were included in the data set for analysis. Given the research protocol it would be inappropriate to draw any generalizations from the quantity of MCI concept defined stories. However, the results provide an initial MCI concept template for sport organizational stories.

When MCI concepts have been specified, it means that there is a break in the domain template for a category. The codes that emerged in this study indicated an underlying structure to MCI concept stories. Specifically, three major kinds of domain-breaks were uncovered which described the MCI concept structure. They were labeled Agency, Membership, and Ritual. Agency describes MCI concepts where there was an attribution of deliberate intention to actions taken by other individuals or conferred upon the inanimate. Membership refers to MCI concepts that provide a declaration of belonging or nonbelonging. Ritual reflects MCI concepts that identify ceremonies and rites connected to superstitions, symbols, and 
behavioral boundaries. Examples both adhering and not adhering to the MCI concept template are provided in Table 1.

\section{Agency}

This first common MCI concept category refers to the attribution of mind, thought, and intentionality to other individuals as well as to the inanimate. Here, the domain break is associated with an attribution that is counter-intuitive given normal expectations. Three subordinate codes described Agency. First, Intentionality involves the perception of understanding the thoughts of others. For example, one story described the conviction of an organizational member that their supervisor was capable of reading their thoughts. Intentionality was also overlaid upon athletes and players whose thoughts and intentions on the field of play were the subject of various presumptions and interpretations that ventured beyond speculation. An example of agency was the attribution of intentionality to a falcon being used for promotional purposes: "It saw we [the home team] were in trouble and slipped its tether and swooped them [the visiting team] which ruined their chances of scoring on the best breakaway they'd had all game." In this example, not only was a bird attributed with a human level of cognition, it was designated with a specific understanding of the situation and the desire to intervene to offer a remedy.

Second, Agency was ascribed to Objects, typically in the form of a power inherent in certain equipment or physical items. For example, one sport venue was considered lucky by all three respondents associated with the organization that used it, and there were several reported examples of equipment, such as shoes, which were viewed as superior, in this case faster than other identical pairs. One story related the adventures of a mischievous trophy which periodically disappeared from a locked cabinet but always returned, while another story highlighted a particularly unlucky office which had a history of encouraging its occupant to leave the organization quickly. An excerpt coded under Agency / Objects relating to an "unlucky" office follows.

It's just one of those things that no one wanted that office even though it is bigger and has a better view than the others. Since I've been here there's been four people who've worked here that've been in that office and have come and gone. They've all seemed happy enough but through one thing or another they've all left after only being here a short time, less than three months in the last case. We call it the office because no one who works in there stays. So now we've hired someone for the new position and they're going to get that office and we've told them about it and they thought we were having a joke, but it's true.

Third, Agency was inherent in the interpretation of Meaning to events. For example, one story focused on a form of provenance associated with finishing the season at the bottom of the ladder because it offered some draft choice advantages. Ostensibly this might appear to be a rational and positive response to an adverse situation. However, it represents a domain-break because the story protagonists attributed a greater meaning to the event; it was discussed in a fatalist way. 


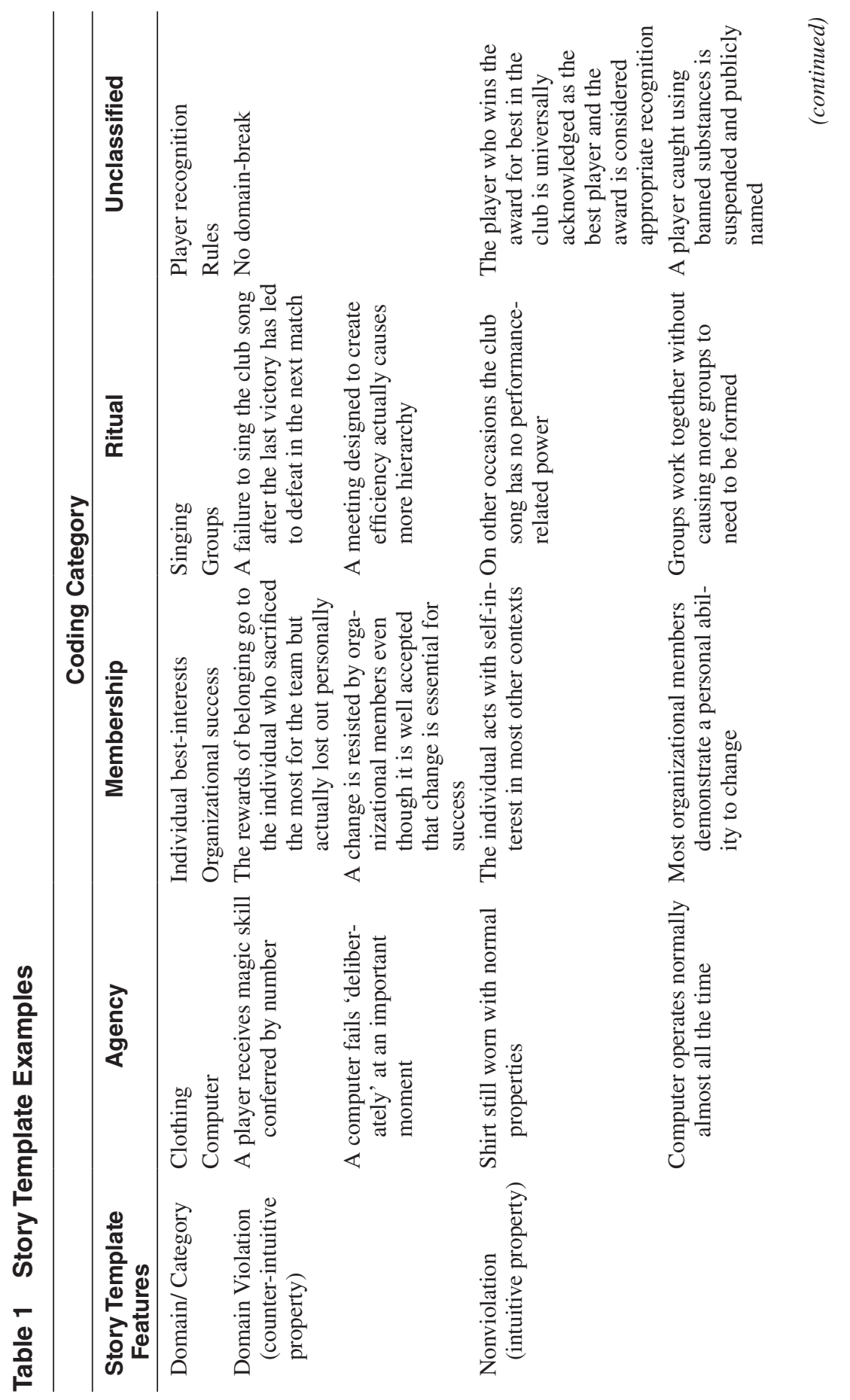




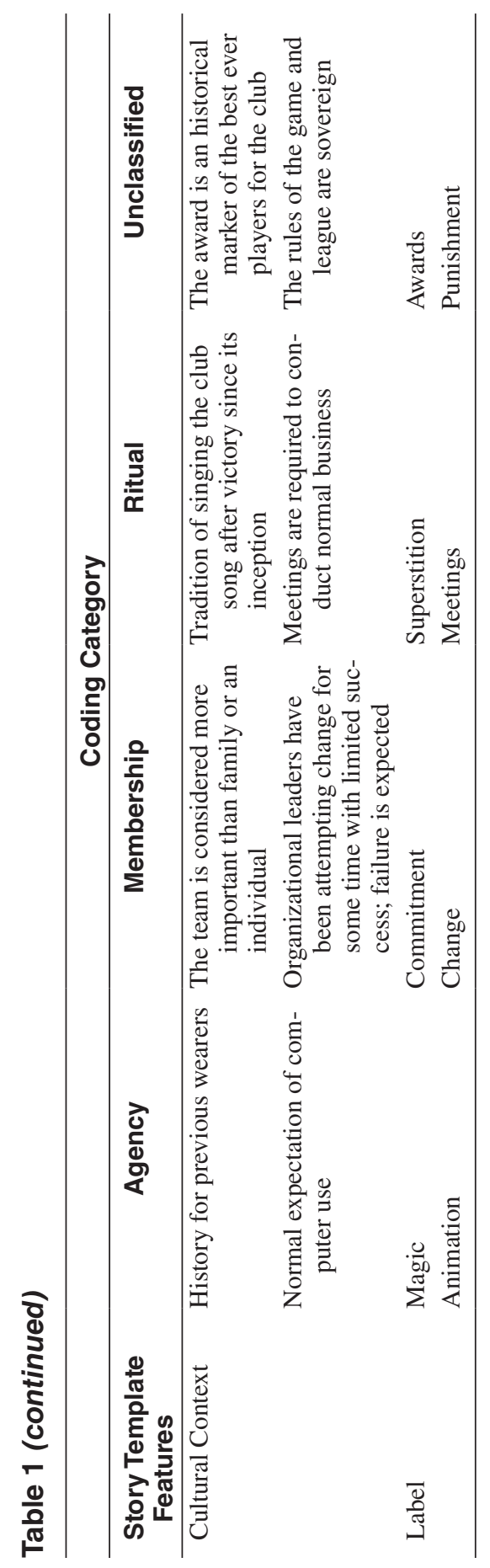




\section{Membership Markers}

Membership Markers refers to content in stories associated with identity and belonging to the organization. The prototypical Membership story demonstrated either sacrifice for the organization or evidence of fraudulent sacrifice and fabricated membership. Domain-breaks were associated with behavior that was in the best interests of the organization but detrimental to the individuals concerned. While sacrifice might be expected, extreme sacrifice at a severe personal expense is not, and represents a domain-break from predicted behavior.

Two codes described Membership Markers. First, Sacrifice concerns stories demonstrating belonging and extremes of attachment and loyalty beyond reasonable expectations. Sacrifice, refers to markers where members have displayed their worthiness and loyalty through personal forfeiture. Sometimes sacrifice was manifested in a form of social exchange, where organizational members engage in some kind of social relationship exemplifying commitment to the organization and its cause, and typically involving friendship, trust, companionship and loyalty. For example, one story highlighted the extraordinary behavior of a long-term organizational member who remortgaged his home to donate the money to his sport club, which was in danger of becoming insolvent:

[It was] his funeral yesterday, a couple of our current committee [members] went to the funeral. He is just a tough hard bastard who has been around forever and he loves the joint. Blokes 30-40 years of age, once they get to know the guy, his toughness and his passion ... rubs off on everybody. He is a hero ... spent all his time at the club and nothing was ever too much. Wife divorced him 'cause she reckoned he loved the club more than her. Never saw his own kids or worried about his career. He was a club man and that was his life. Guess it was about right that he died in the club too.

Second, Nonbelonging referred to stories identifying fabricated membership where loyalty and belonging were fraudulently sought or acquired. For example, one story described an organizational member who had joined the club for its social and gaming facilities, but held an allegiance to another club as evidenced by the memorabilia he wore. The domain-break was registered in other members' responses to this overtly provocative behavior. Not only did they express aggressive intentions, they began to canvass a petition to have any member excluded if they were to enter the club premises wearing the uniform or memorabilia of an opposing team. Yet, the member causing all the controversy was actually doing nothing wrong; his membership was current and his behavior consistent with normal standards in a gaming facility. However, the Nonbelonging response was so extreme that it registered a domain-break: "Anyone coming in here with those colors should be dragged out of here by their scarf and thrown in the [trash] bin with the rest of the [expletive]." The respondent making this overtly antisocial statement was, by normal standards, socially conservative, outwardly warm, and congenial. 


\section{Ritual}

The third form of MCI concept was categorized as Ritual, where the story provided a reference to rituals in which their contents included a domain-breaking component. Three codes emerged to describe the ways that rituals were used as the vehicle for a counter-intuitive concept. First, Superstitions assume the centrality of magic or luck in the resolution of fortune. One story detailed the lengthy rituals associated with socks and underwear for players. In most cases, these superstitions were employed to manage ambiguity and uncertainty or ensure favorable luck:

I got to go through all the laundry of the players and make sure they got all of them, their favorite ones, 'cause they go mental when they can't have their favorites. Once I got the coach yelling at me 'cause I put the wrong socks out for one of 'em and he's got to have his lucky socks even though you can't tell the difference between 'em and others; I put a mark on 'em so I can know which ones they are. I mean here he is making millions and he has to have the same old socks 'cause they're the ones kicking goals not him.

Second, Badges and Symbols highlighted violations to domains where organizational members had undergone a radical rite of passage, such as getting a club tattoo permanently illustrating their allegiance. Like a membership marker, the reference to symbols is indicative of a sacrifice. However, when embedded in a story about ritualistic behavior, the emphasis is placed on the experience of establishing the connection, rather than the outcome. As a result, the domain-break was linked to the decision and process of getting a permanent tattoo in an obvious location, which appeared to lack any forethought, having been driven by a spontaneous urge.

Third, Boundaries and Taboos presented rituals that were associated with the correct boundaries of behavior. Several stories reflected violations to normal category expectations in that behavior was described in extreme and implausible terms. These stories typically highlighted heavy violence, alcohol consumption, sexual promiscuity, or office politics, all with an emphasis on the ritualized event. For example, the following excerpt coded under Rituals illustrates the importance of alcohol consumption in members' rituals. Perhaps more significantly, however, it also reveals the boundaries of those rituals. In this respect, conformity is expressed through the limits of appropriate conduct, and what should not be done.

$(\mathrm{H}) \mathrm{e}$ is close to 80 . He was a foundation member in 1935 . He was one of the people behind the scenes who was around when we made the transition from being just small. . . . Twenty-five years ago, as a Director, drunk one night, leaving the place and fell down the stairs, fractured his skull, in a coma for quite sometime. Thought he wouldn't pull through but he did. Never had a drink since, but he comes out on Fridays after we leave the office. Now he always tells the story of the night and how he thought that the only way of finishing a week was with a drink with the guys from the office, but now he tells them that they'll end up in a coma like he did if they drink too much, 'cause if they have another drink he'll hit them over the head with a chair. 


\section{Discussion}

In some stories, particularly those associated with the product context-sport-it was likely that the participants really did accept the counter-intuitive, domainbreaking feature of their experience. For example, notwithstanding the psychological aspects of performance preparation, when an athlete believes that the number they wear affects their skill through an unnamed power, or that the sequence in which they tie their shoelaces will influence their success, then a counter-intuitive concept can be seen to be present within a wider context that is predominantly intuitive. But in many of the stories, it might be suspected that the respondents contrived a MCI concept, possibly to provide the story with greater impact. For example, one story highlighted the plight of an unlucky employee whose imminently due, quarterly financial report was deleted when the computer he was using inexplicably rebooted and did not contain any recent files when restarted. That this employee apparently considered the failure a personal misfortune beyond normal chance and was the victim of a conspiracy orchestrated by his own personal computer, may ostensibly reflect a domain-breaking registration of agency to an inanimate object. However, it is unlikely that the individual in question or the narrator of the story actually believed that the computer had a mind of its own and took satisfaction in erasing its own hard disk shortly before its owner completed an important report. But since it may seem that way sometimes to minds that seek agency as a matter of normal cognitive functioning, the inclusion of MCI concepts in stories can add a distinctive flavor. After all, exaggeration is a colloquially-accepted property of an entertaining story, and Boyer's (1994, 2000) cognitive optimality hypothesis places this lay assumption within a theoretical structure. What Boyer $(1994,2000)$ has not yet considered is the extent to which a MCI concept can be knowingly self-generated and contrived to add distinctiveness and consequently memorability to a story.

Many of the stories revolved around specific aspects of the product context, in this case the nature of the sports themselves. However, there were also stories focusing on the organizational setting, independent of the product nature. In some instances the former had implications for the latter. For example, some regular season supporters insisted on sitting in particular locations in the home venue because they believed that certain positions were lucky and would therefore have an effect on the outcome of the game. These consumers were notoriously difficult to please as their conception of what was lucky appeared to be fluid.

There were numerous other examples of MCI concepts that were present in organizational stories. These included the perception of athletes and players as superhuman, such as the player who "never" misses, the boss who can read the mind of guilty employees, leaders viewed in both sub- and superhuman terms, and forms of gambling and decision-making where luck is determined by personal variables and it is just a matter of time before success is realized. These examples did not necessarily constitute MCI concepts until they were placed into a story where they could be manipulated to become domain-breaking. Many of the stories that described an organizational event became contrived MCI concepts. A good example is the meeting that was supposed to devise a more streamlined management structure, but actually recommended more hierarchy. The story that explained this meeting was so exaggerated that it might be considered domain- 
breaking despite the likelihood that the organizational members relaying the story would probably not believe that their own story was literally true. For example, one respondent commented that "I think they must have sat around at the start and worked out how they could make things as complicated and unworkable as possible." On the surface, it would perhaps be reasonable to surmise that the purpose of the exaggeration was to invoke a form of domain-break to enhance the story's entertainment value. In an organizational context, however, it is also relevant to consider the potential the pejorative domain-break had on reinforcing a cultural agenda. Using a story to portray a serious meeting designed to improve organizational performance into one resembling a "Dilbert" cartoon reflected a deliberate subversion of the truth. A key theoretical possibility emerging from this study is therefore that the employment of MCI concepts in organizational stories may be indicative of deep cultural values and discontinuities. Their composition and their specific use in sport organizations may highlight their role as revealing cultural markers.

There were some noteworthy aspects of the coding structure that reflect wellestablished views on the periphery of organizational psychology. Agency is consistent with Leslie's (1994, 1996) notion of Theory of Mind, and Dennett's (1987, 2006) presentation of intentionality, where it is assumed that minds treat objects and phenomena in the world as agents with specific motivations and sufficient logic to systematically pursue their goals. To Bering and Johnson (2005), agency mechanisms provide humans with the ability to generate inferences about the behavior of other people. They suspect that the capacity to generate theory of mind has led humans to attribute a meaning to random luck or circumstance. This cognitive capacity may help to explain the occurrence of agency in stories containing MCI concepts, given that it encourages the layering of explanation and intention over other individuals, and meaning over events. To recount an effective and satisfying story, it is essential to include details about the intentions of protagonists and attribute meaning to their actions.

Under Membership Markers, Sacrifice has overlaps with the anthropological concepts of commitment and signaling theory (Sosis, 2003). Cost-signaling assumes that group cooperation is increased when costly signals are required for group members to engender trust and mutual belief. The theory maintains that costly signaling diminishes deception and enhances social cohesion. The more costly the behaviors and commitments required, the greater the degree of commitment and social cohesion that will be observed by organizational members (Irons, 2001; Sosis \& Alcorta, 2003). The theory of cost-signaling provides an explanation as to why humans engage in organizational behaviors that cost them in time, energy, resources, as well as physical and emotional trauma. Sosis (1996) argued that the costs an outsider would have to endure to gain the rewards of membership to a group are too high unless they are accompanied by genuine belief. Moreover, in order for such counter-intuitive behavior to be accepted and propagated in an organization, it would have to become entrenched in its cultural repertoire, of which stories play a pivotal role.

With rituals in mind, Whitehouse (2004) proposed that recurrent concepts take advantage of two particular aspects of memory to enhance recall and subsequent transmission: repetition and arousal. The former is straightforward in the sense that more exposure leads to better recall. The latter is important because the 
more emotionally stimulating a piece of information or event, the easier it is to remember. Ritual performance amplifies belief for the simple reason that to avoid cognitive dissonance nonbelievers will either change their beliefs or stop engaging in the ritual. Absorbing beliefs through repeated exposure to rituals is a process of internalization that provides signals of commitment to a group. In this sense, the presence of rituals in stories is an effective mechanism for their communication to those who do not necessarily practice them, and for those who do to reaffirm their importance.

To date, the concept of rituals has been the subject of research in organizational literature as it relates to organizational culture. Denison (1996) noted that organizational culture research tends to make a distinction between overt manifestations of culture, of which rituals are an exemplar, and those covert and potentially unconscious assumptions and values that drive overt expressions. Thus, a common empirical method has been to identify overt cultural artifacts such as symbols and rituals to extrapolate the deeper meanings they represent (Detert, Schroeder, \& Mauriel, 2000). From this perspective, the deeper structures such as values and meanings are prioritized over their more superficial 'artifacts' such as rituals. This view can be traced to Schein (1984) who in turn operated within a Jungian (Jung, 1968) framework. In the case of this research, organizational stories used the description of rituals as a vehicle for the expression of MCI concepts, thus reinforcing the view that rituals act as a useful mechanism to convey deeper values. For example, telling stories about rituals may increase their memorability because it provides an easy vehicle for fabricating or amplifying potential MCI concepts. Being exposed to a great story about an exciting ritual might be more memorable than actually being personally involved in the ritual.

Everyday experience illustrates that secular rituals associated with sport, health, work, and relationships can be profoundly emotional, and do engender a sense of community among practitioners. There are numerous examples of secular organizations that impregnate their ideological position with supernatural features and other unfalsifiable concepts. For example, governments and armies have employed supernatural propositions to strengthen their dogma, often supported by unverifiable claims of brotherhood, freedom, and certain victory. To this list, we may add sport organizations. The use of unsubstantiated and unfalsifiable ideas may be a central condition for developing powerful communal belief, identity, and solidarity (Sosis \& Ruffle, 2004).

Finally, one of the key challenges associated with the use of MCI concepts is the determination of what is domain-breaking and what is intuitively expected. To some extent, we all would predict, or at least be unsurprised, by some counterintuitive behavior simply on the basis that we expect humans to be unpredictable and irrational at times. Sport is a good exemplification of this ambiguity. For most people, it is counter-intuitive to spontaneously decide to get a permanent and obvious tattoo of a sport team that they follow. On the other hand, most people have also encountered serious sport fans and perhaps would not be surprised to hear about the strength of their allegiance. Similarly, it is counter-intuitive to drink until alcohol poisoning makes one physically ill, but it is a common enough feature in society that few would be surprised that it occurs. It may be worth remembering that these very behaviors are well known because they are spoken about through stories, which are easily remembered and passed on. Context is also rel- 
evant as what might be considered counter-intuitive in a commercial business, may not be in a sport organization. Alternatively, what constitutes a MCI concept within an organizational story could be directly relevant to the strength or 'thickness' of a sport organization's culture.

Strength of culture refers to its intensity or pervasiveness (Schein, 1997). From the earliest studies of organizational culture (e.g., Denison, 1984; Pettigrew, 1979; Schein, 1983), it has been argued that thick cultures more readily command outcomes such as unity, commitment, and co-ordination, culminating in improved performance (Detert et al., 2000). Although there is little reason to conclude that sport organizations possess qualitatively distinctive cultures (Smith \& Shilbury, 2004), there is some evidence that sport organizations tend to generate thick cultures (Colyer, 2000; Lee, 1989; Scott, 1997; Smart \& Wolfe, 2000; Smith \& Stewart, 1995). Just as Wallace, Hunt, and Richards' (1999) study showed that membership to certain organizations with thick cultures like the police can override prevailing cultural forces in the wider environment, belonging to a sport organization might encourage the use of MCI concept stories in greater proportions than similar nonsport organizations. The relationship between the sport context, cultural strength and density of MCI concept stories is worth exploring. If cognitive optimality holds, stronger cultures encourage (and conversely are bolstered by) more memorable stories, which implies that MCI concepts will be found in greater density in sport organizations in general, and thicker sport cultures in particular.

A salient artifact emerging from cultural studies of sport organizations is that they may be mapped using the cultural characteristics and features that have been employed with nonsport organizations. The commonality of cultural dimensions implies perhaps precipitously that sport organizations are culturally undifferentiated from nonsport organizations. While the jury is still out on this pivotal question, the available evidence (Colyer, 2000; Lee, 1989; Scott, 1997; Smart \& Wolfe, 2000; Smith \& Shilbury, 2004; Smith \& Stewart, 1995) suggests that although the overarching dimensions of organizational culture may be ubiquitous, generalities are likely to exist in the expression and weighting of the dimensions in sport organizations. For example, Smith and Shilbury (2004) reported that it was at the subdimensional level where the unique aspects of sporting culture became manifest.

The key theoretical potential of cognitive optimality lies in its treatment of the cultural transmission of information. Sport organizations are socially constructed, contrived realities that encourage members toward systematically collusive beliefs and behaviors. However, the mechanisms that operate upon individuals are enigmatic, often in organizational analyses falling under the mysterious label of culture. Cognitive optimality provides a theoretical construct that assists in understanding the mechanism through which the cultural transmission of information actually occurs. It begins with the assumption derived from cognitive psychology that minds find some information easier to acquire and hold than others. Thus, it operationalizes the mechanism of cultural transmission as a memorability test.

Memorability places restrictions on the cultural transmission of concepts. All else being equal, a more memorable concept enjoys a transmission advantage over a less memorable concept. Cognitive optimality hypothesizes that the composition of cultural concepts affects memorability, and specifically predicts that the 
presence of a counter-intuitive concept within a cultural unit of information that is otherwise intuitive will have a transmission advantage. The results of this study reinforce the possibility that cultural information becomes privileged when it is mostly common-sense, but with a slice of nonsense thrown in as well.

The use of cognitive optimality as a theoretical device in sport settings offers great scope for yielding relevant data about the way sport organizations are shaped by their rich traditions and the sometimes irrational attachments and beliefs they stimulate. If sport organizations are to be differentiated from other institutions with the aim of identifying their specialized management needs, it is necessary for both scholars and practitioners to be able to accurately diagnose their cultural idiosyncrasies. Given that there is sufficient evidence to believe that stories are pivotal cultural transmitters in sport organizations, cognitive optimality provides a theoretical approach that is particularly relevant to sport management practitioners. Cognitive optimality predicts a higher presence of MCI concepts in the cultural information of organizations with stronger cultures and more stories. To extend this speculation, we would expect that sport organizations, in general, possess a greater density of MCI concepts than non-sport organizations and that the relationship between counterintuitive and intuitive is influenced by a greater number of MCI concept stories. In other words, MCI concepts might provide an important piece of the cultural puzzle regarding sport organizations and the conundrum that they appear to possess few if any indigenous cultural markers and yet generate qualitatively different allegiances. To that end, cognitive optimality specifies a novel theoretical tool that could be of more utility to sport organizations that it is to others.

\section{Concluding Comments}

This research sought to explore the proposition that MCI concepts are present in organizational stories and that those stories containing MCI concepts possess a common cognitive structure. The exploration of these propositions is relevant to sport organizational behavior because it will help determine whether there is a case to test the role of MCI concepts in memorability, and therefore in the transmission of organizational stories. The organizational stories collected in this research, when rigidly defined by Gabriel's criteria, do contain minimally counter-intuitive concepts. In accordance with Boyer and Ramble's (2001) domain template, this means that the stories analyzed in this data set contained a concept that violated ordinary expectations about a domain, but otherwise consisted of concepts that remained consistent with intuitive expectations. This study can report suggestive support for Boyer's $(1994,2000)$ cognitive optimality hypothesis, although it remains silent on a quantifiable assessment. However, it has illustrated that minimally counter-intuitive concepts in organizational stories can be commonly delivered through the attribution of agency, the reference of membership, and the reinforcement of ritualistic behavior.

The impact of the domain-breaking concept may be linked to memorability because it provides an anchor around which a story may be told. Atran (2002) proposed that counter-intuitive representations are salient because they facilitate strong inferences that are easy to remember and pass along. As Dennett (2006) so 
bluntly put it: "Some nonsense is more attention-grabbing than other nonsense" (p. 119). To speculate, the most contagious beliefs may be those linked to highly visible intentional agents, such as senior managers, the immediate boss, or elite athletes. In addition, effective stories are reinforced by descriptions of extreme ritualized behavior. Here, beliefs are rehearsed and reproduced by proxy. In addition, certain MCI concepts which provide clear group-membership markers of commitment are optimally suited to repetition because they offer scope for social advancement. MCI concepts embedded in stories from sport organizations might provide an accessible cultural surrogate. Moreover, the deliberate manipulation of domains to create breaks may reflect strategic expressions about and reactions to dominant cultural values. The use of MCI concepts in stories could help organizational researchers in sport to locate pivotal cultural markers, while sport managers would benefit from understanding how organizational members wield and transmit stories to emphasize their own cultural interpretations.

Cognitive optimality, as elucidated here through stories, leads organizational scholars of sport to a series of important theoretical propositions: (1) There is a cognitive component to the cultural transmission of concepts; (2) The presence of minimally counter-intuitive content may be connected to memorability and therefore the successful transmission of cultural information; (3) The use of MCI concepts in stories may serve as a portal for understanding storytellers' interpretations of culture and therefore the construction of their organizational realities; (4) The application of MCI concepts in stories may serve as a surrogate for behavioral prescription thereby providing organizational members with the opportunity to learn cultural norms through a nonthreatening and efficient mechanism rather than through personal experience; (5) The memorability of any story can be amplified through the deliberate insertion of MCI concepts; and (6) MCI concepts could provide a mechanism for strengthening cultural values by offering belonging and solidarity through communal acceptance of unsubstantiated but unfalsifiable beliefs.

As with all interpretive, qualitative research, it is relevant to express caution about the generalizability of the results. In principle, the cognitive features of stories identified in this study could be common to all sport organizations. As always, more research is warranted in different organizations and industries, preferably in different ethnic and national contexts. If the results obtained here are indicative of others, then organizational context may prove central to the expression of cognitive optimality in stories. Here, the research context revealed a host of stories directly connected to sport. An important question would be whether MCI concepts are expressed through the same three chief patterns in all organizational contexts. It remains sensible to pursue work on contextual influences, or what Berger and Heath (2005) called habitat variations.

More in-depth ethnographic work would also be advantageous to explore the utility of MCI concept content specifically, and organizational stories in general, as indicative cultural markers. Several methodological possibilities might be explored. First, a sport organization might be subject to an assessment of organizational culture through a well-established mechanism like a prominent instrument or a suite of qualitative approaches. These results would make an interesting comparison with an assessment of dominant cultural values that arise from organizational stories. In particular, the cognitive optimality theory predicts that there 
should be a correspondence between common content in MCI concepts and dominant cultural priorities. An example can be found in religion where the most common domain-breaks are associated with supernatural agents.

Second, the cultural content of MCI concept stories could be compared with the cultural content of non-MCI concept stories. This could be extended into a longitudinal comparison to determine whether MCI concept stories are more enduring. It would also be interesting to note the life-span of non-MCI concept and MCI concept stories. If MCI concepts do play a role in story longevity and transmission, then it would ultimately be salient to investigate whether the sport context is an influential factor. In short, are sport organizational stories more susceptible to MCI concepts than those stories from other organizational settings? The relevance of the sport context may be helpful in differentiating the management of sport organizations from other types of organization.

A final complication might be the unit of analysis. If entire belief sets are equally relevant to, or more relevant than individual stories, then the best approach would demand that each respondent's set of stories be examined as an independent unit. Irrespective of the assumption that all minds host concepts in similar ways, cognitive optimality may still turn out to have a degree of fluidity.

MCI concepts are salient to understanding the interaction between cognitive activity and the cultural transmission of information. As Sperber (2006, p. 52) declared, "Culture is the precipitate of cognition and communication in a human population." Of particular interest is the evidence from this study that the recall of cultural concepts is a constructive process where both prosaic and exotic material is reframed in terms of familiar 'schemata.' In terms of work in cognitive psychology, this is not a new observation (see for example, Bergman \& Roediger, 1999). However, the presence of MCI concepts-where elements of a story contradict intuitive and conceptual expectations-should undermine script structures. In the case of stories from sport organizations, MCI concepts are neither peripheral nor disruptive. The evidence from this study suggests that MCI concepts provide a focal point for stories and may even act as a mechanism of cultural canalization.

\section{References}

Atran, S. (2002). In gods we trust: The evolutionary landscape of religion. Oxford, UK: Oxford University Press.

Atran, S., \& Norenzayan, A. (2004). Religion's evolutionary landscape: Counterintuition, commitment, compassion, communion. The Behavioral and Brain Sciences, 27, 748749.

Barrett, J.L., \& Nyhof, M.A. (2001). Spreading nonnatural concepts: The role of intuitive conceptual structures in memory and transmission of cultural materials. Journal of Cognition and Culture, 1, 69-100.

Berger, J. A., \& Heath, C. (2005). Idea habitats: How the prevalence of environmental cues influences the success of ideas. Cognitive Science: A Multidisciplinary Journal, 29(2), 195-221.

Bergman, E., \& Roediger, H. (1999). Can Bartlett's repeated reproduction experiments be replicated? Memory \& Cognition, 27, 937-947.

Berger, P.L., \& Luckmann, T. (1967). The social construction of reality: A treatise in the sociology of knowledge. New York: Anchor Books. 
Bering, J.M., \& Johnson, D.D. (2005). 'O lord you perceive my thoughts from afar': Recursiveness and the evolution of supernatural agency. Journal of Cognition and Culture, 5, 118-142.

Beyer, J., \& Trice, H. (1993). How an organization's rites reveal its culture. Organizational Dynamics, 15(4), 5-23.

Boje, D. (1991). The storytelling organization: A study of storytelling performance in an office supply firm. Administrative Science Quarterly, 36, 106-126.

Boje, D. (2001). Narrative methods for organizational and communication research. London: Sage.

Boyer, P. (1994). The naturalness of religious ideas: A cognitive theory of religion. Berkeley, CA: University of California Press.

Boyer, P. (2000). Natural epistemology or evolved metaphysics? Developmental evidence for early-developed, intuitive, category-specific, incomplete, and stubborn metaphysical presumptions. Philosophical Psychology, 13, 277-297.

Boyer, P. (2001). Religion explained: The evolutionary origins of religious thought. New York: Basic Books.

Boyer, P. (2003). Religious thought and behavior as by-products of brain function. Trends in Cognitive Sciences, 7(3), 119-124.

Boyer, P. (2005). A reductionistic model of distinct modes of religious transmission. In H. Whitehouse \& R.N. McCauley (Eds.), Mind and religion: Psychological and cognitive foundations of religiosity (pp. 3-29). Walnut Creek, CA: AltaMira Press.

Boyer, P., \& Ramble, C. (2001). Cognitive templates for religious concepts: Cross-cultural evidence for recall of counter-intuitive representations. Cognitive Science: A Multidisciplinary Journal, 25, 535-564.

Browning, L.D. (1991). Organizational narratives and organizational structure. Journal of Organizational Change Management, 4(3), 59-67.

Czarniawska, B. (2004). Narratives in social science research. London: Sage.

Daft, R.L., \& Weick, K.E. (1984). Toward a model of organizations as interpretation systems. Academy of Management Review, 9, 284-295.

D'Andrade, R.G. (1995). The development of cognitive anthropology. Cambridge, UK: Cambridge University Press.

Dawkins, R. (1982). The extended phenotype. Oxford: Oxford University Press.

Deetz, S. (1996). Describing differences in approaches to organization science: Rethinking Burrell and Morgan and their legacy. Organization Science, 7, 191-207.

Denis, J-L., Lamothe, L., \& Langley, A. (2001). The dynamics of collective leadership and strategic change in pluralistic organizations. Academy of Management Journal, 44, 809-837.

Denison, D. (1996). What is the difference between organizational culture and organizational climate? A native's point of view on a decade of paradigm wars. Academy of Management Review, 21, 619-654.

Dennett, D. (1987). The intentional stance. Cambridge, MA: MIT Press.

Dennett, D. (2006). Breaking the spell: Religion as a natural phenomenon. New York: Viking.

Denning, S. (2000). The springboard: How storytelling ignites action in knowledge-era organizations. Boston: Butterworth-Heinemann.

Denning, S. (2002). The narrative lens: Storytelling in 21 st century organizations. Knowledge Directions, 3(2), 92-101.

Denison, D. (1984). Corporate culture to the bottom line. Organizational Dynamics, 13(2), $5-22$.

Detert, J., Schroeder, R., \& Mauriel, J. (2000). A framework for linking culture and improvement initiatives in organizations. Academy of Management Review, 25, 850-863.

Durkheim, E. (1961). The elementary forms of the religious life (J. W. Swain, Trans.). New York: Collier Books. 
Eysenck, M.W., \& Keane, M. (2005). Cognitive psychology. New York: Psychology Press.

Fischer, G. (1997). Abstention from sex and other pre-game rituals used by college male varsity athletes. Journal of Sport Behavior, 20, 176-184.

Gabriel, Y. (1995). The unmanaged organization: Stories, fantasies and subjectivity. Organization Studies, 16, 477-501.

Gabriel, Y. (2000). Storytelling in organizations: Facts, fictions, and fantasies. London: Oxford University Press.

Gabriel, Y. (2004). Narratives, stories and texts. In D. Grant, C. Hardy, C. Oswick, \& L. Putnam (Eds.), The Sage handbook of organizational discourse (pp. 61-67). London: Sage.

Gabriel, Y., \& Griffiths, D. (2004). Stories in organizational research. In C. Cassell \& G. Symon (Eds.), Essential guide to organizational research (pp. 114-126). London: Sage.

Gardner, W.L., \& Avolio, B.J. (1998). The charismatic relationship: A dramaturgical perspective. Academy of Management Review, 23, 32-58.

Gargiulo, T. (2005). The strategic use of stories in organizational communication and learning. Armonk, NY: M.E. Sharpe.

Gargiulo, T. (2006). Stories at work: Using stories to improve communication and build relationships. Connecticut: Praeger.

Hardy, C., Lawrence, T., \& Grant, D. (2005). Discourse and collaboration: The role of conversations and collective identity. Academy of Management Review, 30, 58-77.

Hatch, M.J. (1993). The dynamics of organizational culture. Academy of Management Review, 18, 657-693.

Heath, C., Bell, C., \& Sternberg, E. (2001). Emotional selection in memes: The case of urban legends. Journal of Personality and Social Psychology, 81, 1028-1041.

Hopkinson, G. (2003). Stories from the front-line: How they construct the organization. Journal of Management Studies, 40, 1943-1969.

Irons, W. (2001). Religion as a hard-to-fake sign of commitment. In R. Nesse (Ed.), Evolution and the capacity for commitment (pp. 292-309). New York: Russell Sage.

Jung, C.G. (1968). Analytical psychology: Its theory and practice. New York: Vintage Books.

Lee, M. (1989). Organizational culture and performance in NCAA sporting teams. Campus Review, 5(1), 27-35.

Leslie, A. (1994). TOMM, TOBY, and agency: Core architecture and domain specificity. In L. Hirschfield \& S. Gelman (Eds.), Mapping the mind (pp. 119-148). Cambridge, UK: Cambridge University Press.

Leslie, A. (1996). A theory of agency. In D. Sperber, D. Premack, \& A. Premack (Eds.), Causal cognition (pp. 121-141). Oxford: Clarendon Press.

Lincoln, Y.S., \& Guba, E.G. (1985). Naturalistic inquiry. London: Sage.

McCauley, R.N., \& Lawson, E.T. (2002). Bringing ritual to mind. Cambridge, UK: Cambridge University Press.

Miles, M., \& Huberman, M. (1994). Qualitative data analysis. Thousand Oaks, CA: Sage.

Nair, R. (2002). Narrative gravity: Conversation, cognition, culture. New York: Routledge.

Norenzayan, A., \& Atran, S. (2002a). Cognitive and emotional processes in the cultural transmission of natural and nonnatural beliefs. In M. Schaller \& C. Crandall (Eds.), The psychological foundations of culture (pp. 149-169). Hillsdale, NJ: Lawrence Erlbaum.

Norenzayan, A., \& Atran, S. (2002b). Cognitive and emotional processes in the cultural transmission of natural and nonnatural beliefs. In M. Schaller \& C. Crandall (Eds.), The psychological foundations of culture (pp. 149-169). Hillsdale, NJ: Lawrence Erlbaum. 
Norenzayan, A., Atran, S., Faulkner, J., \& Schaller, M. (2006). Memory and mystery: The cultural selection of minimally counterintuitive narratives. Cognitive Science: A Multidisciplinary Journal, 30, 531-553

Ogbonna, E., \& Harris, L.C. (2002). Managing organizational culture: Insights from the hospitality industry. Human Resource Management Journal, 12(1), 33-53.

Pettigrew, A.M. (1979). On studying organizational cultures. Administrative Science Quarterly, 24, 570-581.

Poulton, M.S. (2005). Organizational storytelling, ethics and morality: How stories frame limits of behavior in organizations. Electronic Journal of Business Ethics and Organization Studies, 10(2), 4-9.

Pyysiäinen, I. (2002). Religion and the counter-intuitive. In I. Pyysiäinen \& V. Anttonen (Eds.), Current approaches in the cognitive science of religion (pp. 110-132). London: Continuum.

Pyysiäinen, I. (2003). How religion works: Towards a new cognitive science of religion. Leiden, The Netherlands: Brill.

Pyysiäinen, I., Lindeman, M., \& Honkela, T. (2003). Counterintuitiveness as the hallmark of religiosity. Religion, 33, 341-355.

Schein, E. (1983). Organizational culture. Organizational Dynamics, 12, 13-28.

Schein, E. (1984). Coming to a new awareness of organizational culture. San-Francisco: Jossey-Bass.

Schein, E. (1985). Organizational culture and leadership. San Francisco: Jossey-Bass.

Schein, E. (1988). Organizational psychology (3rd ed.). Englewood Cliffs, NJ: Prentice Hall.

Schein, E. (1997). Organizational culture and leadership (3rd ed.). San Francisco: JosseyBass.

Schwartzman, H.B. (1993). Ethnography in organizations. Newbury Park, CA: Sage.

Scott, D. (1997). Managing organizational culture in intercollegiate athletic organizations. Quest, 49, 403-415.

Scott, R.W. (2001). Institutions and organizations (2nd ed.). Thousand Oaks, CA: Sage.

Smart, D., \& Wolfe, R. (2000). Examining sustainable competitive advantage in intercollegiate athletics: A resource based view. Journal of Sport Management, 14, 133-153.

Smith, A., \& Shilbury, D. (2004). Mapping cultural dimensions in Australian sporting organizations. Sport Management Review, 7, 133-165.

Smith, A., \& Stewart, R. (1995, December). Sporting club cultures: An exploratory case study. Australian Leisure, pp. 31-37.

Sosis, R. (2003). Why aren't we all Hutterites? Costly signaling theory and religious behavior. Human Relations, 14, 91-127.

Sosis, R., \& Alcorta, C.S. (2003). Signaling, solidarity and the sacred: The evolution of religious behavior. Evolutionary Anthropology, 12, 264-274.

Sosis, R., \& Ruffle, B. (2004). Evolution of cooperation: Field experiments on Israeli kibbutzim. Socioeconomic Aspects of Human Behavioral Ecology. Research in Economic Anthropology, 23, 89-117.

Sperber, D. (1996). Explaining culture: A naturalistic approach. Cambridge, MA: Blackwell.

Sperber, D. (1997). Intuitive and reflective beliefs. Mind \& Language, 12, 67-83.

Sperber, D. (2006). The epidemiology of beliefs: A naturalistic approach. In D.J. Slone (Ed.), Religion and cognition (pp. 36-53). London: Equinox Publishing.

Strauss, A., \& Corbin, J. (1990). Basics of qualitative research: Grounded theory procedures and techniques. Newbury Park, CA: Sage.

Strauss, A., \& Corbin, J. (1994). Grounded theory methodology: An overview. In N. Denzin \& Y. Lincoln (Eds.), Handbook of qualitative research (pp. 273-287). London: Sage.

Swan, J. (1997). Using cognitive mapping in management research: Decisions about technical innovation. British Journal of Management, 8, 183-198. 
Swap, W., Leonard, D., Shields, M., \& Abrams, L. (2001). Using mentoring and storytelling to transfer knowledge in the workplace. Journal of Management Information Systems, 18, 95-114.

Todd, M., \& Brown, C. (2003). Characteristics associated with superstitious behavior in track and field athletes: Are there NCAA divisional level differences? Journal of Sport Behavior, 26, 168-187.

Trice, H.M., \& Beyer, J.M. (1984). Studying organizational cultures through rites and ceremonials. Academy of Management Review, 9, 653-669.

Tyler, J.A. (2006). Storytelling and organizations: Introduction to the special issue. Storytelling, Self. Society, 2(2), 1-4.

Wallace, J., Hunt, J., \& Christopher, R. (1999). The relationship between organisational culture, organisational climate, and managerial values. International Journal of Public Sector Management, 12, 548-564.

Weick, K.E. (1995). Sensemaking in organizations. London: Sage.

Wellman, H. (1990). The child's theory of mind. Cambridge, MA: MIT Press.

Whitehouse, H. (2004). Modes of religiosity: A cognitive theory of religious transmission. Walnut Creek, CA: Alta Mira Press.

Whitehouse, H. (2005). The cognitive foundations of religiosity. In H. Whitehouse \& R.N. McCauley (Eds.), Mind and religion: The psychological and cognitive foundations of religion (pp. 207-232). Walnut Creek, CA: AltaMira Press.

Womack, M. (1992). Why athletes need ritual: A study of magic among professional athletes. In S.J. Hoffman (Ed.), Sport and religion (pp. 191-202). Champaign, IL: Human Kinetics Books.

Yanow, D. (2000). Seeing organizational learning: A 'cultural' view. Organization, 7, $247-268$. 
Copyright of Journal of Sport Management is the property of Human Kinetics Publishers. Inc. and its content may not be copied or emailed to multiple sites or posted to a listserv without the copyright holder's express written permission. However, users may print, download, or email articles for individual use. 